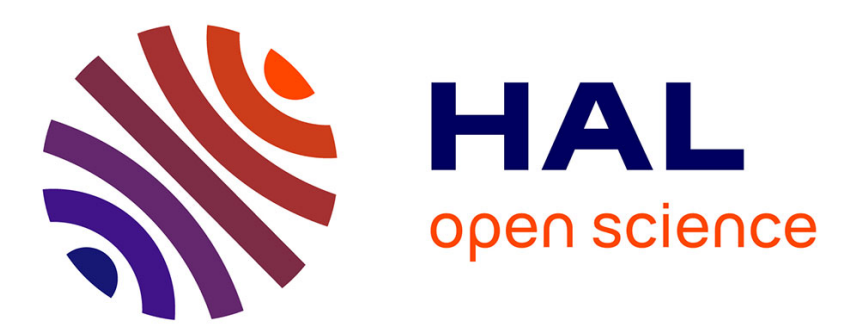

\title{
Advances in Electronic Government (e-Government) Adoption Research in SAARC Countries
}

Nripendra P. Rana, Yogesh K. Dwivedi, Sunil Luthra, Banita Lal, Mohammad Alryalat

\section{- To cite this version:}

Nripendra P. Rana, Yogesh K. Dwivedi, Sunil Luthra, Banita Lal, Mohammad Alryalat. Advances in Electronic Government (e-Government) Adoption Research in SAARC Countries. 16th Conference on e-Business, e-Services and e-Society (I3E), Nov 2017, Delhi, India. pp.147-158, 10.1007/978-3-31968557-1_14. hal-01768494

\section{HAL Id: hal-01768494 \\ https://hal.inria.fr/hal-01768494}

Submitted on 17 Apr 2018

HAL is a multi-disciplinary open access archive for the deposit and dissemination of scientific research documents, whether they are published or not. The documents may come from teaching and research institutions in France or abroad, or from public or private research centers.
L'archive ouverte pluridisciplinaire HAL, est destinée au dépôt et à la diffusion de documents scientifiques de niveau recherche, publiés ou non, émanant des établissements d'enseignement et de recherche français ou étrangers, des laboratoires publics ou privés.

\section{(c)(1)}

Distributed under a Creative Commons Attribution| 4.0 International License 


\title{
Advances in Electronic Government (e-Government) Adoption Research in SAARC Countries
}

\author{
Nripendra P. Rana ${ }^{1}$, Yogesh K. Dwivedi ${ }^{1}$, Sunil Luthra ${ }^{2}$, Banita Lal ${ }^{3}$, Mohammad \\ Abdallah Ali Alryalat ${ }^{4}$ \\ ${ }^{1}$ Emerging Market Research Center (EMaRC), School of Management, Swansea \\ University Bay Campus, Fabian Way, Swansea, SA1 8EN, UK \\ ${ }^{2}$ Department of Mechanical Engineering, Government Engineering College, Nilokheri, \\ Haryana, PIN-132117, India \\ ${ }^{3}$ Nottingham Business School, Nottingham Trent University, 50 Shakespeare \\ St, Nottingham, NG1 4FQ, UK \\ ${ }^{4}$ Faculty of Business, Al-Balqa' Applied University, Salt, PIN-19117, Jordan \\ \{1n.p.rana@swansea.ac.uk, ${ }^{1}$ y.k.dwivedi@swansea.ac.uk, ${ }^{2}$ sunilluthra1977@gmail.com, \\ ${ }^{3}$ banita.lal@ntu.ac.uk, ${ }^{4}$ mohammad.alryalat@hotmail.com\}
}

\begin{abstract}
This paper profiles the research activities that have been published on e-government adoption in the context of South Asian Association for Regional Cooperation (SAARC) countries. Our analysis includes variables such as the years of publication, journals most often publishing papers on e-government adoption, countries in which the research activity was conducted, the authors most active in the subject area, keywords analysis, methodological analysis, technology and respondents contexts, analysis of theories or models used and analysis of limitations and future research directions extracted from 48 research papers that were extracted from Scopus database using some key terminologies related to e-government, adoption and eight SAARC countries. This is the first study that has comprehensively examined the analysis of e-government adoption literature in these eight countries' context. The results of this research provide some promising lines of inquiry that have been largely neglected along with those that have received a much larger attention.
\end{abstract}

Keywords: Adoption, Afghanistan, Bangladesh, Bhutan, E-Government, eGov, Digital Government, India, Literature Review, Maldives, Nepal, Online Government, Pakistan, SAARC countries, Sri Lanka

\section{Introduction}

Electronic government (hereafter, e-government) is one of the most fascinating concepts to have appeared in the area of public administration and has become a substantially evident aspect of governance in the last few years [1, 2]. The introduction of e-government is a move undertaken by various governments across the world toward becoming more service oriented and focused for their widespread implementation of digital services to its users [3]. E-government can be defined as the delivery of government information and services to citizens through the Internet (as 
the Internet is one of the preconditions to the acceptance and use of e-government services) or other digital means $[4,5]$. It provides citizens with convenient access to such information and services [6], the ability to search and acquire them at their own convenience.

E-government provides a number of benefits to its users including reducing administrative burdens and corruption, delivering more accountable, transparent and easily accessible cost-effective delivery of public services, employing citizen empowerment, improving convenience, and ensuring quicker adaptation to meet citizens' needs and better governance that help the government to become more result-oriented [3,7]. Nowadays, as governments are increasingly turning to egovernment led administrative reforms, citizens' slow uptake or adoption of governments' online services poses a great threat for reform managers who are not only responsible for improving the quality of public service delivery but also cutting down on operating expenses [8]. Citizens who do not use these services end up wasting their valuable time in government offices, which could have well be used in the economically productive activity. Moreover, under-utilisation of e-government services also results in a low rate of return on government funds that were invested to develop those services. Considering that it takes substantial funds for a government to create new e-government services, it might be difficult to sustain severely underutilised e-government service [9, 10]. A number of studies (e.g. [7], [11], [12]) both in context of developed and developing countries' contexts have emphasized the slow adoption of e-government services right from the early days of its evolution. This is the reason why a number of studies have explored the reasons behind the slow adoption of e-government services particularly in developing countries' context through research dispersed in the various outlets.

This study will focus on the analysis of literature on e-government adoption emerging from the countries that are members of South Asian Association for Regional Cooperation (SAARC), which consists of eight countries namely India, Pakistan, Sri Lanka, Bangladesh, Afghanistan, Bhutan, Nepal and Maldives. We have selected the research on e-government adoption from these member countries from SAARC because they represent a part of Asian continent and agreed to work on five areas including telecommunication, which could be considered as a backbone for effective e-government implementation. They also share socioeconomic, demographic and cultural practices and they all share some attributes of developing countries. Hence, analysis of literature from these countries would provide insights that would be applicable to them. Furthermore, combining literature from other countries would provide a mix picture and outcomes may not be fully applicable these countries.

The remaining sections of the paper are structured as follows: Section 2 will describe the literature search approach. Section 3 will perform literature analyses using meta-data analysis in terms of years of publications of research, journals where such research studies were published, countries of research publication and list of prolific authors who published research on e-government adoption. The following subsections will evaluate the keyword analysis, methodological analysis, technology context, types of respondents and analysis of theories and models in these egovernment adoption studies. Section 4 will provide brief discussion of findings, limitations of existing studies, their future research agenda, contribution of this research to literature and recommendations provided to government based on this 
literature analysis. The final section (i.e. Section 5) will provide conclusive remarks of this research including limitations and future research directions for this study.

\section{Literature Search Approach}

We used the set of keywords such as "electronic government", "e-government", "eGov", "eGovernment", “mobile government", "m-government”, “digital government" and "online government" using the logical OR operator supported with other sets of keywords on the major theme of adoption/acceptance including "adoption", intention", "behavior", "acceptance" and list of eight SAARC countries in context for which the available literature have to be considered for this study including "India", "Pakistan", "Sri Lanka", "Bangladesh", "Afghanistan", "Bhutan", "Nepal" and "Maldives" using AND operator in Scopus database. We gathered 54 articles from different journals based on the above search. However, we discarded six studies because either they were not related to e-government research in SAARC countries' context or their theme was not quite related to e-government adoption/context. This way we left out with 48 articles that made the basis for the literature analysis for this study.

\section{Literature Analysis}

This section will present analysis on meta-data, keywords, methodology, technology context, respondent types and use of theories/models gathered from 48 articles on egovernment adoption research in the context of SAARC countries.

\subsection{Meta-Data Analysis}

The number of papers published on e-government adoption in context of SAARC countries indicates that the trend of publications was quite tentative over the years with 2016 being the most productive year with highest 11 studies published in one or the other research outlets. However, the lowest one paper was published in year 2006. The collective trend of publications of research in the last two years indicates increasing levels of interest and research activity in this area in the recent time [13].

As far as the breakdown of our search output according to the journals in which the papers on e-government adoption appeared during 2006-2017 period. A total of 21 journals were found as the appropriate outlets for e-government adoption research. The largest number of papers (8) on e-government adoption appeared in the journal called Electronic Government, an International Journal and least one paper each published in 10 different journals. Other journals have published something between two to six papers on e-government adoption. Our finding reveals that research outlets are quite diverse and in addition to journals that largely publish issues related to government and public sector, they are largely related to information systems and technology. 
The findings regarding countries where the research studies were piloted indicated that the largest numbers of research studies were conducted in India (23) followed by Pakistan (10), Bangladesh (7) and Sri Lanka (4). However, only one study each was conducted in context of Afghanistan and Nepal and no research on e-government adoption has yet been conducted in the context of Bhutan and Maldives. Given that Sri Lanka holds the highest rank in terms of e-government development index among the SAARC countries, it is surprising that there has not been much research based on this country. Hence, there is an opportunity for additional research based in such countries where there is no research or only a handful of research available in order to further expand the existing knowledge base.

So far as authors actively involved in conducting and publishing e-government adoption related research is concerned, it appears that the most productive author in egovernment adoption research is Dwivedi with 13 papers closely followed by two authors Gupta and Rana both with six papers each and Williams and Shareef with five and four papers respectively. Thereafter, four authors contributed three papers each and 13 authors contributed two papers each while 72 authors published just one paper in the set of journals comprising our search data. Due to space limitations the authors with one publication has not been listed.

\subsection{Keyword Analysis}

In order to assess the most frequently used keywords, all the keywords from 48 studies were gathered. A total of 30 keywords were used two or more times. Egovernment in its various forms including m-government was the most frequently used keywords with all 48 papers utilized them. This is followed by adoption (19), India (14), communication technologies (13), trust (9) and developing countries (9) are some of the other more frequently used keywords used in e-government adoption research here. The use of keywords such as e-government and adoption as the two leading keywords is not surprising as these keywords are related to the major themes of the research. We have also found some of the obvious keywords related to countries where such research has been conducted and linked to the use of key theories/models, factors, research methods and analysis techniques related to this area of research. We also found 75 keywords with only one occurrence and have not included them in the text because of space limitations. Moreover, even though some other keywords such as digital divide, citizen satisfaction, corruption, Internet usage are relatively less frequently occurring they seem more interesting and hold significance in terms of their further exploration in context of SAARC countries.

\subsection{Research Methods Analysis}

Research methods include research approach, methodology, analysis techniques and analysis tools used by these e-government adoption studies (see Table 1). The findings indicate that majority (i.e. 27 studies) of the research (e.g. [3], [7]) on egovernment adoption are quantitative in nature followed by eleven studies (e.g. [14]) using qualitative research. However, only one study each was found under the 
category of conceptual [15], descriptive [16], and interpretive research [17]. Therefore, it quite clearly indicates that e-government research in SAARC countries is slowly moving from informational to transactional stage. As far as methodologies are concerned, survey (33) was found as the most commonly used methodology (e.g. [18]). This was followed by some others but relatively less frequently used methodologies including case study (5) (e.g. [19]), interview (2) (e.g. [14]) and content analysis (2) (e.g. [20]), literature review (2) (e.g. [21]) and interpretive structural modelling (ISM) (e.g. [17]) as some others. Survey was commonly used in different forms including questionnaire survey, online survey, email survey and field survey. The scrutiny of analysis techniques and tools indicates that the studies have mainly used regression analysis (14) (e.g. [22], [24]) and structural equation modelling (12) (using AMOS (8), Smart PLS (1) and LISREL (3)) (e.g. [7], [18], [23]) as the key techniques to evaluate their results.

Table 1. Research methods used

\begin{tabular}{lll}
\hline Research methods & Details & Example reference(s) \\
\hline Research approach & Quantitative [27] & {$[3][7][10][18][32]$} \\
\hline & Qualitative [11] & {$[14][20][31][36]$} \\
\cline { 2 - 3 } & Conceptual [1] & {$[15]$} \\
\cline { 2 - 3 } & Descriptive [1] & {$[16]$} \\
\cline { 2 - 3 } & Interpretive [1] & {$[17]$} \\
\hline \multirow{2}{*}{ Methodology } & Survey (Online, Questionnaire, Email, & {$[7][18][27][32]$} \\
\hline & Field survey etc.) [33] & {$[14][21]$} \\
\hline & Interview [3] & {$[20]$} \\
\cline { 2 - 3 } & Content analysis [2] & {$[16][19][40]$} \\
\cline { 2 - 3 } & Case study [5] & {$[17]$} \\
\cline { 2 - 3 } & ISM [1] & {$[21][25]$} \\
\cline { 2 - 3 } & Literature review [2] & {$[3][7][32]$} \\
\hline \multirow{2}{*}{ Analysis technique } & Regression (i.e. multiple regression, & {$[22][35]$} \\
& hierarchical regression) analysis [14] & {$[30]$} \\
\hline & Structural equation modelling [12] & {$[3][7]$} \\
\cline { 2 - 3 } & Factor analysis [1] & {$[41]$} \\
\hline Analysis tool & SPSS [14] & {$[18][33]$} \\
\hline & AMOS [8] & \\
\cline { 2 - 3 } & Smart PLS [1] & {$[31]$} \\
\cline { 2 - 3 } & LISREL [3] & \\
\hline
\end{tabular}

\subsection{System or Technology Context}

This section presents different systems or technologies examined across 48 studies that formed our search results. It is clear from the investigation that e-government in its generic (e.g. [8], [20]) and specific forms (e.g. [3], [7]) make the most of systems. However, some studies have also examined other technologies such as cloud computing, information and communication technology (ICT) or online services in government context. For example, MdYusof et al. [25] and Gupta et al. [26] examined adoption of cloud computing and ICT in context of government of public sector 
organisations whereas Manandhar et al. [27] explored success factors of online services in the Nepalese perspective. The findings indicate that despite of egovernment development in SAARC countries in last few years, research is largely limited to the evaluation of generic e-government and m-government services and less effort has been paid toward evaluating specific e-government or m-government applications.

\subsection{Respondent Type}

This section presents different types of respondents from whom the data for studies were gathered (see Table 2). The analysis indicated that largest 26 studies (e.g. [7], [28]) used citizens' data whereas 10 studies (e.g. [10], [26]) utilized employees as their respondents. Only two studies (e.g. [29]) used student data and the remaining 10 studies (e.g. [19], [20]) were based on literature reviews, content analysis of egovernment portals, descriptive research or case studies. Given that development of egovernment in SAARC countries is not very old they have started riding on the wagon wheel of evaluating their e-government initiatives using primary data however as some research studies are still trying to understand the development of egovernment initiatives using literature review, case studies, content analysis and descriptive research before the performance of systems could be evaluated using primary data.

Table 2. Respondent type

\begin{tabular}{lcl}
\hline Respondent Type & N & Example source(s) \\
\hline Citizenl Consumer & 26 & {$[7][8][18][22][30][32][35]$} \\
\hline Employeel Professional & 10 & {$[10][21][27]$} \\
\hline Student & 2 & {$[24][29]$} \\
\hline Content analysis, descriptive, literature reviews, case study & 10 & {$[19][20][40]$} \\
\hline
\end{tabular}

\subsection{Theories/Models Used}

This section provides account for different theories and/or models that have been used across the studies on e-government adoption in SAARC countries context (see Table $3)$. The findings indicated that the unified theory of acceptance and use of technology (UTAUT) (10) (e.g. [7], [30]) has been used the most number of times closely followed by the technology acceptance model (TAM) (9) (e.g. [8]). The theories like diffusion of innovation (DOI) (e.g. [31]) and IS success model (e.g. [27]) have been used five times each. However, the theories/models such as TRA [32], TPB [33], SCT [3], trustworthiness model [34], transaction cost theory [31] and perceived characteristics of innovating [8] have been used only once. The findings clearly indicate that the studies of e-government adoption are largely dependent on information systems/technology (IS/IT) adoption models. 
Table 3. Theories/Models Used

\begin{tabular}{lcl}
\hline Theory/Model used & N & Example sources \\
\hline UTAUT & 10 & {$[7][19[][29][30]$} \\
\hline TAM & 9 & {$[8][33]$} \\
\hline DOI & 5 & {$[10][31][33][39]$} \\
\hline IS success model & 5 & {$[23][24][27]$} \\
\hline
\end{tabular}

\subsection{Limitations and Recommended Future Research of Reviewed Studies}

The findings related to limitations of existing research indicate that the largest number of limitations is related to context specific sample collected from one or limited number of organisations, cultures, countries, communities or settings (i.e. G2C, G2E) (e.g. [2], [3], [35]) followed by limitations related to generalizability of findings to the other contexts or settings [7,32]. Some studies have also highlighted the issues of cross-sectional data (e.g. [8]), data collected from non-adopters of the system (e.g. [7]), lack of additional and more suitable variables in the proposed model (e.g. [36]), student sample (e.g. [8]), small or inadequate sample and limited variance obtained by the model on dependent variables (e.g. [30]). In addition, there are some other limitations that have occurred only once or twice and so have not been included into text due to space limitations. Some of these limitations include lower response rate [18], no use of moderating variables [30], no validation for conceptual model [37], exploratory research or research in progress [18] and the qualitative nature of study [14] to name a few.

The largest number of studies proposed their future research directions in terms of the need for diverse sample (e.g. [22], [30]), which are aligned with the limitations of existing research as presented earlier where the highest 14 studies articulated that their sample was context specific. This is followed by some other future research directions including the need for the proposed model to be tested using longitudinal data (e.g. [28]), use of additional, new and more specific constructs (e.g. [3]), testing models in some other similar contexts (e.g. [18]), need of examining more specific cultural and geographical contests (e.g. [28]) and extending the model to be tested using adopters data (e.g. [7]) to name a few. The other future research directions, which occurred only once or twice include the need of using non-student data [36], need of embedding use behavior in the proposed model [32], need for quantitative approach in the research [14] and need for larger sample [29] to name a few.

\section{Discussion}

The findings presented above explored a number of dimensions of the analysis of literature on e-government adoption in SAARC countries. The findings suggest the increasing levels of interest in e-government adoption research in last two years. The further analysis of it indicates that majority of research in last few years have been published repeatedly by a very small group of researchers on the various emerging egovernment systems in context of India, Bangladesh, Pakistan and Sri Lanka. However, this effort needs to be diversified and more researchers should join hands in 
publishing research in this area. The findings along the journals most often published paper on e-government adoption indicates that in addition to the government and/or public sector related journals the papers have also highly diversely published across IS/IT, information management and human behavior related journals. The findings also revealed that majority of studies on e-government adoption in SAARC countries context have not quite been able to find their homes in internationally respected peer reviewed journals. The natural and obvious reason for this could be less mature egovernment related research in these countries' perspectives [38]. In terms of country analysis, it was found that India was the leading country for which the e-government adoption research was conducted whereas no research was undertaken for countries like Bhutan and Maldives. Hence, there are ample opportunities to conduct research for such countries, which are completely untapped and also those (e.g. Nepal and Afghanistan), which are under researched.

The findings also suggest that the most productive authors in terms of number of papers published in last 11 years were Dwivedi, Gupta, Rana, Williams and Shareef. The Google Scholar citation for Dwivedi also suggests that he has had the largest number of citation counts for his research. Moreover, only one out of these most productive authors is based in India and others are from the UK or Bangladesh. This clearly indicates that even though the e-government adoption research is being conducted for the SAARC countries, the authors belong to the academic institutions of other countries. Hence, there is a need for more authors within the countries to highlight and explore research agenda related to e-government, as it is one of the most relevant ways in which government services could be delivered from the government to its citizens. The regular appearance of certain related keywords such as egovernment in general and specific e-government services such as e-District, ePension, income tax filing etc. and m-government clearly suggests that majority of these studies are focused on investigating e-government and m-government services. However, a large body of under-represented keywords (i.e. 75) such as digital divide, citizen satisfaction, D\&M model, corruption, Internet usage are worthy of further exploration in the future research. For example, the less frequent use of keywords such as satisfaction and D\&M model also indicates that the e-government adoption research has not quite reached to its maturity in SAARC countries whereby the research could examine the citizens' satisfaction using D\&M model.

In terms of research methods, our investigation revealed that quantitative approach has dominated the e-government adoption research in context of SAARC countries. Similarly, survey methodology appears to have been much preferred over other available alternatives. As the e-government research is still in its nascent state in the eight developing countries of SAARC, there is a further need to have some more literature review, case study, focus group, observation, and interview based research to establish the boundary of e-government research particularly in the countries where such research is under-published or not published at all. It is also very evident that the majority of research used quantitative analysis techniques such as regression analysis or structural equation modeling using tools including SPSS, AMOS, Smart PLS and LISREL. The further exploration of qualitative techniques and tools is also needed to have the in-depth analysis of the research questions. Exploring the system or technology for e-government adoption research indicates that majority of studies examined generic e-government services. Given the substantial growth of mobile use 
by all classes of people throughout the world and its very nature of providing alternative way of providing public services through online wireless media [18], there is further need to explore the success of such services in delivering government services to end users in SAARC countries as well. The analysis of respondent types also indicates that individual context/unit of analysis including citizens, customers, students and employees with citizen/customer as the most frequently researched context. The more research is needed to further examine how e-government adoption for professionals is different to citizens. The analyses of theories and models have revealed that most of the quantitative studies on e-government adoption have inherited the IS/IT theories of adoption (e.g. UTAUT) [42] into e-government context and there has hardly been any effort of theory development for this type of research. A very recent effort has been made by few studies (e.g. [2], [7], [28]) toward developing specific theories/models particularly applicable to e-government context in India. However, these theories/models need further validation for establishing their generalisability using diverse datasets from other countries as well. Limitations acknowledged by the studies included in our investigation appear to center on the nature of collected data and data collection issues - such as context specific or biased sample, non-generalisable findings or results, only non-user's or non-adopter's views, student sample and small sample to name some of such frequently used limitations. Therefore, there would appear to be much scope for researchers to undertake the future research on e-government adoption that addresses these limitations [38]. This recommendation is also supported by the investigation of future research agenda of 48 studies in question where two most frequently occurring research agendas are related to data collection. However, the other most relevant and common research agenda emerging from the analysis of future research was largely related to extending the existing models with new constructs and testing them in some other similar contexts. The future research should contribute to the existing literature by doing so.

\section{Conclusion, Limitations and Future Work}

The intention of this paper is to provide an overview of the current state of egovernment adoption research by presenting the results of comprehensive analysis of 48 papers appearing across 21 journals during a period of last 11 years in the context of SAARC countries. We have presented the results of our investigation along a series of dimensions including the years of publication, journals most often publishing papers on e-government adoption, countries in which the research activity was conducted, the authors most active in the subject area, keywords analysis, methodological analysis, technology and respondents contexts, analysis of theories or models used and analysis of limitations and future research directions extracted from all the papers.

In keeping with previous research of this nature, we posit that our findings demonstrate some promising lines of inquiry and also those that were largely neglected along with those that have received a much larger attention. The overall analysis of literature on e-government adoption clearly indicates that this research is still in its early stage of development with very little area of maturity. Our results on country analysis indicate that majority of research have been published in Indian 
context so there are ample opportunities for researchers from other countries to embark on performing research for some least or under-represented countries. Also only few studies (e.g. [39], [40]) have researched e-government adoption in context of SAARC countries along Western countries. Given that Western countries have very developed infrastructure and implementations and their citizens are much aware about the use of such services, more such multicultural studies would be very helpful to undertake in the future as well. The exploration of limitations and future research agenda for the existing research studies in SAARC countries also provided us to avoid those limitations and follow the suggested research plan to perform original research studies on e-government adoption in the future.

We very much believe that this paper can prove to be a useful source of information for the readers who want to undertake e-government adoption research in context of any SAARC country in the future. However, we also acknowledge that this study has a number of limitations as well. Firstly and most obvious of all is that our research is limited to the exploration of existing research published only in journals and not considered a volume of research published in conferences and book chapters. The future research can incorporate all possible research to perform the analysis. Secondly, this research is a literature analysis and not the actual review of studies on e-government adoption in SAARC countries' context. The future research can perform systematic literature review of all existing studies to set the research agenda for the future. Finally, this research has not analysed the quantitative research for weight- and meta-analysis to understand the significant factors across the countries that have most significant and non-significant impact on e-government adoption. The future research can perform such analysis considering only all empirical studies available in these eight countries context. The future research can also look at community analysis and association mining among e-government adoption constructs gathered from the studies in SAARC countries' context [43].

\section{References}

1. Morgeson, F.V. III, Van Amburg, D., Mithas, S.: Misplaced trust? Exploring the structure of the E-Government-Citizen trust relationship. Journal of Public Administration Research and Theory, 21(2), 257--283, (2010).

2. Rana, N.P., Dwivedi, Y. K., Lal, B., Williams, M. D., Clement, M.: Citizens' adoption of an electronic government system: Towards a unified view. Information Systems Frontiers, 19(3), 549--568, (2015a).

3. Rana, N.P., Dwivedi, Y.K.: Citizen's adoption of an e-government system: Validating extended social cognitive theory (SCT). Government Information Quarterly, 32(2), 172-$181,(2015)$.

4. Joseph, R.C.: A structured analysis of e-government studies: Trends and opportunities. Government Information Quarterly, 30(4), 435--440, (2013).

5. West, D.: E-Government and the transformation of service delivery and citizen attitudes. Public Administration Review, 64(1), 15--27, (2004).

6. Schaupp, L.C., Carter, L.: The impact of trust, risk and optimism bias on e-file adoption. Information Systems Frontiers, 12(3), 299--309, (2010).

7. Dwivedi, Y.K., Rana, N.P., Janssen, M., Lal, B., Williams, M.D., Clement, M.: An empirical validation of a unified model of electronic government adoption 
(UMEGA). Government Information Quarterly, doi:10.1016/j.giq.2017.03.001， 1--20, (2017).

8. Ojha, A., Sahu, G.P., Gupta, M.P.: Citizens' adoption of pay-to-use e-government services: An empirical study. International Journal of Electronic Government Research, 7(2), 15--35, (2011).

9. Bertot, J.C., and Jaeger, P.T.: The E-Government paradox: Better customer service doesn't necessarily cost less. Government Information Quarterly, 25(2), 149--154, (2008).

10. Ojha, A., Sahu, G.P., Gupta, M.P.: Antecedents of paperless income tax filing by young professionals in India: An exploratory study. Transforming Government: People, Process and Policy, 3(1), 65--90, (2009).

11. Akkaya, C., Obermeier, M., Wolf, P., Krcmar, H.: Components of Trust Influencing eGovernment Adoption in Germany. In M. Janssen, H. J. Scholl, M. A. Wimmer and Y-H. Tan (eds.). EGOV 2011, LNCS 6846, 88--99, (2011).

12. Williams, M. D., Dwivedi, Y. K., Lal, B., Schwarz, A.: Contemporary trends and issues in IT adoption and diffusion research. Journal of Information Technology, 24(1), 1--10, (2009).

13. Bwalya, K.J., Healy, M.: Harnessing e-government adoption in the SADC region: a conceptual underpinning. Electronic Journal of e-government, 8(1), 23--32, (2010).

14. Kumar, R., Sachan, A., Mukherjee, A.: Qualitative approach to determine user experience of e-government services. Computers in Human Behavior, 71, 299--306, (2017).

15. Diwan, S.A., Perumal, S., Siber, D.S.: Smart E-service implementation as mobile agent in a smart E-government platform. International Journal of Applied Engineering Research, 11(7), 5250--5255, (2012).

16. Hasan, S.: ICT policies and their role in governance: The case of Bangladesh. Science, Technology and Society, 19(3), 363--381, (2014).

17. Faisal, M.N., Rahman, Z.: E-government in India: Modelling the barriers to its adoption and diffusion. Electronic Government, 5(2), 181--202, (2008).

18. Shareef, M.A., Dwivedi, Y.K., Stamati, T., Williams, M.D.: SQ mGov: A comprehensive service-quality paradigm for mobile government. Information Systems Management, 31(2), 126--142, (2014).

19. Ahmed, M.A., Janssen, M., Van Den Hoven, J.: Value sensitive transfer (VST) of systems among countries: Towards a framework. International Journal of Electronic Government Research, 8(1), 26--42, (2012).

20. Tripathi, R., Gupta, M. P., Bhattacharya, J.: Interoperability adoption among government and corporate portals in India: A study. Journal of Enterprise Information Management, 25(2), 98--122, (2012).

21. Tripathi, R., Gupta, M. P., Bhattacharya, J.: Identifying factors of integration for an interoperable government portal: A study in Indian context. International Journal of Electronic Government Research, 7(1), 64--88, (2011).

22. Dwivedi, Y. K., Khan, N., Papazafeiropoulou, A.: Consumer adoption and usage of broadband in Bangladesh. Electronic Government, 4(3), 299--313, (2007).

23. Rehman, M., Kamal, M. M., Esichaikul, V.: Adoption of e-government services in Pakistan: A comparative study between online and offline users. Information Systems Management, 33(3), 248--267, (2016).

24. Rehman, M., Esichaikul, V., Kamal, M.: Factors influencing e-government adoption in Pakistan. Transforming Government: People, Process and Policy, 6(3), 258--282, (2012).

25. MdYusof, M.I.B., Baharudin, A.S., Karkonasasi, K.: Factors affecting the cloud computing technology adoption among public organizations. International Journal of Applied Engineering Research, 11(14), 8145--8148,(2016).

26. Gupta, B., Dasgupta, S., Gupta, A.: Adoption of ICT in a government organization in a developing country: An empirical study. Journal of Strategic Information Systems, 17(2), 140--154, (2008). 
27. Manandhar, S. P., Kim, S., Hwang, J.: Success factors of online services in Kathmandu, Nepal: An empirical analysis. International Journal of Business Information Systems, 18(4), 422--436, (2015).

28. Rana, N.P., Dwivedi, Y.K., Williams, M.D., Weerakkody, V.: Adoption of online public grievance redressal system in India: Toward developing a unified view. Computers in Human Behavior, 59, 265--282, (2016).

29. Azam, A., Qiang, F., Abdullah, M.I.: Determinants of e-government services adoption in Pakistan: An integrated model. Electronic Government, an International Journal, 10(2), 105--124, (2013).

30. Gupta, K.P., Bhaskar, P., Singh, S.: Critical factors influencing E-government adoption in India: An investigation of the citizens' perspectives. Journal of Information Technology Research, 9(4), 28--44, (2016).

31. Shareef, M.A., Kumar, U., Kumar, V., Dwivedi, Y.K.: Identifying critical factors for adoption of e-government. Electronic Government, an International Journal, 6(1), 70--96, (2009).

32. Alryalat, M.A.A., Rana, N.P., Dwivedi, Y.K.: Citizen's adoption of an e-government system: Validating the extended theory of reasoned action (TRA). International Journal of Electronic Government Research, 11(4), 1--23, (2015).

33. Shareef, M.A., Dwivedi, Y.K., Laumer, S., Archer, N.: Citizens' adoption behavior of mobile government (mGov): A cross-cultural study. Information Systems Management, 33(3), 268--283, (2016b).

34. Sultana, M.R., Ahlan, A.R., Habibullah, M.: A comprehensive adoption model of Mgovernment services among citizens in developing countries. Journal of Theoretical and Applied Information Technology, 90(1), 49--60, (2016).

35. Rana, N.P., Dwivedi, Y.K., Williams, M.D., Weerakkody, V.: Investigating success of an e-government initiative: Validation of an integrated IS success model. Information Systems Frontiers, 17(1), 127--142, (2015b).

36. Ahmad, M.O., Markkula, J., Oivo, M.: Factors affecting e-government adoption in Pakistan: A citizen's perspective. Transforming Government: People, Process and Policy, 7(2), 225--239, (2013).

37. Ranaweera, H.M.B.P.: Perspective of trust towards e-government initiatives in Sri Lanka. SpringerPlus, 5(1), 1--11, (2016).

38. Williams, M.D., Rana, N.P., Dwivedi, Y.K.: The Unified Theory of Acceptance and Use of Technology: A Systematic Review. Journal of Enterprise Information Management, 28(3), 443--488, (2015).

39. Shareef, M.A., Kumar, V., Dwivedi, Y.K., Kumar, U.: Service delivery through mobilegovernment (mGov): Driving factors and cultural impacts. Information Systems Frontiers, 18(2), 315--332, (2016a).

40. Weerakkody, V., Dwivedi, Y. K., Kurunananda, A.: Implementing e-government in Sri Lanka: Lessons from the UK. Information Technology for Development, 15(3), 171--192, (2009).

41. Chauhan, S., Kaushik, A.: Evaluating citizen acceptance of unique identification number in India: An empirical study. Electronic Government, 12(3), 223--242, (2012).

42. Dwivedi, Y. K., Rana, N. P., Jeyaraj, A., Clement, M., Williams, M. D.: Re-examining the Unified Theory of Acceptance and Use of Technology (UTAUT): Towards a Revised Theoretical Model. Information Systems Frontiers, DOI: 10.1007/s10796-017-9774-y, 1-$16,(2017)$.

43. Grover, P., Kar, A. K.: Big Data Analytics: A Review on Theoretical Contributions and Tools Used in Literature. Global Journal of Flexible Systems Management, DOI: 10.1007/s40171-017-0159-3, 1--27, (2017). 